\title{
Klebsiella pneumoniae liver abscess in diabetic patients: association of glycemic control with the clinical characteristics
}

\author{
Yi-Tsung Lin ${ }^{1,2^{*}}$, Fu-Der Wang ${ }^{1,2}$, Ping-Feng $W^{1}{ }^{1}$ and Chang-Phone Fung ${ }^{1,2}$
}

\begin{abstract}
Background: Klebsiella pneumoniae liver abscess (KPLA) has been reported with increasing frequency in East Asian countries in the past 3 decades, especially in Taiwan and Korea. Diabetes is a well-known risk factor for KPLA and highly associated with septic metastatic complications from KPLA. We investigated the association of glycemic control in diabetic patients with the clinical characteristics of KPLA in Taiwan.
\end{abstract}

Methods: Adult diabetic patients with KPLA were identified retrospectively in a medical center from January 2007 to January 2012. Clinical characteristics were compared among patients with different levels of current hemoglobin A1c $\left(H_{b A_{1 c}}\right)$. Risk factors for metastatic infection from KPLA were analyzed.

Results: Patients with uncontrolled glycemia $\left(\mathrm{HbA}_{1 \mathrm{c}} \geq 7 \%\right)$ were significantly younger than those with controlled glycemia $\left(\mathrm{HbA}_{1 c}<7 \%\right)$. Patients with uncontrolled glycemia had the trend to have a higher rate of gas-forming liver abscess, cryptogenic liver abscess, and metastatic infection than those with controlled glycemia. Cryptogenic liver abscess and metastatic infection were more common in the poor glycemic control group $\left(\mathrm{HbA}_{1 c}\right.$ value $\left.>10 \%\right)$ after adjustment with age. $\mathrm{HbA}_{1 \mathrm{c}}$ level and abscess $<5 \mathrm{~cm}$ were independent risk factors for metastatic complications from KPLA.

Conclusions: Glycemic control in diabetic patients played an essential role in the clinical characteristics of KPLA, especially in metastatic complications from KPLA.

\section{Background}

Klebsiella pneumoniae liver abscess (KPLA) has been reported with increasing frequency in East Asian countries in the past 3 decades, especially in Taiwan and Korea [1-7]. K. pneumoniae is the dominant cause of pyogenic liver abscesses in Taiwan and has contributed to the endemic feature of the disease in Taiwan [8-10]. Since 1986, many researchers in Taiwan and several other areas have noted the distinctive syndrome of KPLA, complicated by bacteremia, sepsis, and metastatic infection of brain, eyes, lungs and other organs, especially in patients with diabetes $[2,5,6,11-15]$. The mortality rate of KPLA has decreased in recent years in Taiwan $[6,8]$; nevertheless, despite aggressive therapy, the outcomes of these patients frequently involve catastrophic disability.

\footnotetext{
* Correspondence: ytlin8@vghtpe.gov.tw

'Division of Infectious Diseases, Department of Medicine, Taipei Veterans General Hospital, No. 201, Sec. 2, Shih-Pai Road, 112 Taipei, Taiwan

${ }^{2}$ School of Medicine, National Yang-Ming University, Taipei, Taiwan
}

Our recent study also has indicated that catastrophic disability due to ocular or neurological complications from KPLA could lead to poor long-term prognosis [10].

Patients with diabetes are at increased risk for common infection due to impaired host defense mechanisms [16]. Diabetes is a well-known risk factor for pyogenic liver abscess [17] and highly associated with KPLA $[5,18,19]$. One animal study of KPLA has suggested that diabetes might provide a specialized environment that allows $K$. pneumoniae strains to disseminate from the intestines into the blood [20]. In addition, diabetes is the most common underlying disease among patients with septic metastatic complications from KPLA [12,13,19,21], and predisposes patients with KPLA to develop septic metastasis [22]. Compared with the monomicrobial cryptogenic noninvasive KPLA, cryptogenic KPLA with septic metastasis is characterized by an $\sim 20$-fold increased association with diabetes [23]. 
Previous studies have compared the characteristics of liver abscess patients with and without diabetes [17,18,24]. The influence of diabetes on KPLA has also been described [1]. However, no research is available on the impact of glycemic control on the characteristics of KPLA in diabetic patients. To monitor glycemic control, hemoglobin A1c $\left(\mathrm{HbA}_{1 \mathrm{c}}\right)$ gives an estimate of average blood glucose during the preceding 3 months, and is widely accepted as the primary indicator of the level of glycemic control for optimal management of diabetes [25].

Therefore, we conducted this study to investigate whether glycemic control assessed by $\mathrm{HbA}_{1 \mathrm{c}}$ affected the clinical characteristics of diabetic patients with KPLA.

\section{Methods}

\section{Study design, patient populations, and data collection}

This study was a retrospective cohort analysis of consecutive diabetic patients with KPLA at Taipei Veterans General Hospital, a tertiary medical center with a 2900bed capacity. Those patients with KPLA were identified by reviewing culture records from the Department of Microbiology from January 2007 to January 2012. We excluded patients aged $<20$ years. Age, sex, underlying diseases, clinical presentations, laboratory findings, including images, and management were collected. Assessment of blood glucose control was based on $\mathrm{HbA}_{1 \mathrm{c}}$ levels at the time of infection or as close to the time of infection as possible, within one month before this episode of KPLA. The major outcome measurements included intensive care unit admission within 48 hours, length of hospitalization, and mortality. Septic metastatic infection is highly associated with diabetic patients with KPLA; therefore, we analyzed the risk factors among these patients. This study was approved by Institutional Review Board of Taipei Veterans General Hospital.

\section{Definitions}

An episode of KPLA was defined as the presence of $\geq 1$ liver abscess, detected by sonography or computed tomography, and culture-confirmed $K$. pneumoniae isolated from an abscess or blood. Only the first episode of KPLA in a particular patient, diagnosed at our hospital during the period of study, was included. For the diagnosis of diabetes, the American Diabetes Association diagnostic criteria were used [25]. Patients with diabetes were defined as those with a history of either type 1 or type 2 diabetes and/or those taking either insulin and/or oral hypoglycemic agents. If diabetes was diagnosed during the patient's treatment for this episode of KPLA, newly diagnosed diabetes was recorded. Chronic kidney disease was indicated by a creatinine level $\geq 2.0 \mathrm{mg} / \mathrm{dL}$. Chronic lung disease was defined as chronic obstructive pulmonary diseases, bronchiectasis, or any structural lung diseases with the exception of bronchogenic carcinoma.
Cryptogenic origin of infection was defined as that in which no obvious extrahepatic source of infection could be identified [22]; biliary tract origin was defined if clinical features of cholecystitis/cholangitis or extrahepatic biliary ductal abnormalities were identified on radiographic images. Multiple abscesses mean $>2$ abscess in liver parenchyma confirmed by imaging. Metastatic infection was defined as a distant site of infection isolated with the same pathogen as the pyogenic liver abscess (К. pneumoniae).

\section{Microbiology laboratory procedures}

The VITEK 2 system (bioMérieux, Marcy l'Etoile, France) was used to confirm bacterial identifications among the available isolates. magA is the serotype K1 wzy allele and was determined among the $K$. pneumonaie isolates as described previously [6].

\section{Statistical analysis}

We performed a 2-tailed $\chi^{2}$ test or Fisher's exact test (for contingency data) and Student's $t$ test or ANOVA method (for continuous data) to compare the groups with different $\mathrm{HbA}_{1 \mathrm{c}}$ levels. A $P$ value $<0.05$ was considered statistically significant; all probabilities were 2-tailed. Cochran-Mantel-Haenszel test with median age as the stratum was used to analyze the association between glycemic control and other factors. To identify possible independent predictors for metastatic infection, multivariate analysis was undertaken using logistic regression to adjust for the presence of confounding variables. Age, sex and all potential predictors with $p \leqq 0.1$ on univariate analysis were considered for inclusion in the multivariate model. All statistical analyses were performed with SPSS version 17.0 for Windows.

\section{Results}

Comparison of clinical characteristics of KPLA in diabetic patients with controlled or uncontrolled glycemia

During the study period, 108 diabetic patients from all of the 221 KPLA cases were identified. We excluded six patients due to lack of $\mathrm{HbA}_{1 \mathrm{c}}$. The remaining 102 patients all had type 2 diabetes. $\mathrm{HbA}_{1 \mathrm{c}}$ level $<7 \%$ is generally considered as the target of glycemic control for diabetic patients $[25,26]$. We compared patients with controlled glycemia $\left(\mathrm{HbA}_{1 \mathrm{c}}<7 \%\right)$ and uncontrolled glycemia $\left(\mathrm{HbA}_{1 \mathrm{c}} \geq 7 \%\right)$. The level of $\mathrm{HbA}_{1 \mathrm{c}}$ in the group with uncontrolled glycemia was significantly higher than that in the group with controlled glycemia $(10.0 \pm 2.1$ vs $6.5 \pm 0.3 \%, p<0.001)$.

Table 1 showed the clinical features between these two groups. Patients with uncontrolled glycemia were younger $(62.8 \pm 14.9$ vs $70.6 \pm 9.6$ years, $p=0.017)$ than those with controlled glycemia. Patients with poor glycemic control had the trend to have a higher rate of cryptogenic 
Table 1 Baseline characteristics, clinical presentation, and outcome of diabetic patients with controlled or uncontrolled glycemia

\begin{tabular}{|c|c|c|c|c|}
\hline & $\begin{array}{l}\text { Controlled } \\
\text { glycemia }(n=19)\end{array}$ & $\begin{array}{l}\text { Uncontrolled } \\
\text { glycemia }(n=83)\end{array}$ & $p$ value & $\begin{array}{l}p \text { value, } \\
\text { (adjusted age) }\end{array}$ \\
\hline Male & $12(63.2)$ & $59(71.1)$ & 0.498 & 0.952 \\
\hline Age in years & $70.6 \pm 9.6$ & $62.8 \pm 14.9$ & 0.017 & \\
\hline \multicolumn{5}{|l|}{ Underlying diseases } \\
\hline Malignancy & $1(5.6)$ & $10(12.7)$ & 0.683 & 0.367 \\
\hline Alcoholism & $1(5.3)$ & $4(4.8)$ & 1.000 & 0.655 \\
\hline Chronic kidney disease & $1(5.6)$ & $8(10.3)$ & 1.000 & 0.311 \\
\hline Liver cirrhosis & $0(0)$ & $2(2.4)$ & 1.000 & 0.494 \\
\hline Congestive heart failure & $0(0)$ & $2(2.4)$ & 1.000 & 0.392 \\
\hline Chronic lung disease & $0(0)$ & $1(1.2)$ & 1.000 & 0.549 \\
\hline Newly diagnosed diabetes & $4(21.1)$ & $21(25.3)$ & 1.000 & 0.995 \\
\hline \multicolumn{5}{|l|}{ Origin } \\
\hline Cryptogenic & $15(78.9)$ & $77(92.8)$ & 0.087 & 0.090 \\
\hline Biliary tract origin & $1(5.3)$ & $5(6.0)$ & 1.000 & 0.785 \\
\hline \multicolumn{5}{|l|}{ Abscess locations } \\
\hline Right lobe & $11(57.9)$ & $44(53.0)$ & 0.791 & 0.407 \\
\hline Left lobe & $5(26.3)$ & $19(22.9)$ & & \\
\hline Both lobes & $3(15.8)$ & $20(24.1)$ & & \\
\hline \multicolumn{5}{|l|}{ Abscess size } \\
\hline$<5 \mathrm{~cm}$ & $9(47.4)$ & $36(43.4)$ & 1.000 & 0.707 \\
\hline $5 \sim 10 \mathrm{~cm}$ & $9(47.4)$ & $39(47.0)$ & & \\
\hline$>10 \mathrm{~cm}$ & $1(5.3)$ & $8(9.6)$ & & \\
\hline Gas forming & $0(0)$ & $12(14.5)$ & 0.116 & 0.126 \\
\hline Multiple abscesses & $8(42.1)$ & $29(34.9)$ & 0.558 & 0.791 \\
\hline \multicolumn{5}{|l|}{ Initial laboratory value } \\
\hline Leukocyte count, $\times 10^{3} / \mu \mathrm{L}$ & $12.4 \pm 3.8$ & $13.5 \pm 6.0$ & 0.165 & 0.417 \\
\hline Platelet, $\times 10^{3} / \mu \mathrm{L}$ & $195 \pm 87$ & $229 \pm 121$ & 0.145 & 0.442 \\
\hline C-reactive protein, mg/dL & $18.8 \pm 9.2$ & $20.0 \pm 9.8$ & 0.487 & 0.779 \\
\hline Glucose, mg/dL & $193 \pm 76$ & $318 \pm 168$ & 0.007 & 0.004 \\
\hline \multicolumn{5}{|l|}{ Treatment } \\
\hline Antibiotics + drainage & $16(84.2)$ & $69(83.1)$ & 1.000 & 0.894 \\
\hline Antibiotics + operation & $1(5.3)$ & $3(3.6)$ & 0.568 & 0.525 \\
\hline Antibiotics only & $2(10.5)$ & $11(13.4)$ & 1.000 & 0.557 \\
\hline Metastatic infections & $0(0)$ & $12(14.5)$ & 0.116 & 0.077 \\
\hline \multicolumn{5}{|l|}{ Outcome } \\
\hline Hospitalization days & $26.2 \pm 12.1$ & $28.1 \pm 19.0$ & 0.692 & 0.428 \\
\hline Intensive care unit admission & $2(10.5)$ & $12(14.5)$ & 1.000 & 0.849 \\
\hline Mortality & $0(0)$ & $3(3.6)$ & 1.000 & 0.359 \\
\hline
\end{tabular}

Data are presented as mean \pm SD or frequency with percentage (\%).

liver abscess (92.8 vs $78.9 \%, p=0.087$ ), gas-forming liver abscess (14.5 vs $0 \%, p=0.116)$, and metastatic infection ( 14.5 vs $0 \%, p=0.116)$ than those with controlled glycemia. The underlying disease did not differ between the two groups. Most of the lesions were located in the right lobe, but the characteristics of abscess did not differ significantly between the two groups. No mortality was identified in the group with controlled glycemia. The treatment strategy did not differ among the groups with different $\mathrm{HbA}_{1 \mathrm{c}}$ levels. 
Length of stay in hospital and intensive care unit admission rate did not differ significantly between the two groups. As the age is significantly different between the groups, we compared all the characteristics after adjustment with age, which showed the consistent results.
Only 41 isolates of $K$. pneumonaie were available for microbiological analysis, and we found that 21 isolates were positive for $m a g A$. The distribution of $m a g A$ in $K$. pneumoniae isolates did not differ between controlled and uncontrolled groups $(66.7 \%$ vs $46.9 \%, p=0.454)$.

Table 2 Baseline characteristics, clinical presentation, and outcome of diabetic patients with KPLA according to different $\mathrm{HbA}_{1 \mathrm{c}}$ levels

\begin{tabular}{|c|c|c|c|c|c|}
\hline Factor & $\mathrm{HbA}_{1 \mathrm{c}}<7 \%(\mathrm{n}=19)$ & $\mathrm{HbA}_{1 \mathrm{c}}=7 \sim 10 \%(\mathrm{n}=44)$ & $\mathrm{HbA}_{1 \mathrm{c}}>10 \%(\mathrm{n}=39)$ & $p$ value & $p$ value, (adjusted age) \\
\hline Male & $12(63.2)$ & $30(68.2)$ & $29(74.4)$ & 0.660 & 0.999 \\
\hline Age in years & $71.3 \pm 9.9$ & $68.2 \pm 11.4$ & $56.3 \pm 15.8$ & $<0.001$ & \\
\hline \multicolumn{6}{|l|}{ Underlying diseases } \\
\hline Malignancy & $1(5.6)$ & $8(20.0)$ & $2(5.1)$ & 0.100 & 0.560 \\
\hline Alcoholism & $1(5.3)$ & $0(0)$ & $4(10.3)$ & 0.081 & 0.378 \\
\hline Chronic kidney disease & $1(5.6)$ & $7(17.5)$ & $1(2.6)$ & 0.067 & 0.889 \\
\hline Liver cirrhosis & $0(0)$ & $2(4.5)$ & $0(0)$ & 0.667 & 0.676 \\
\hline Congestive heart failure & $0(0)$ & $2(4.5)$ & $0(0)$ & 0.667 & 0.970 \\
\hline Chronic lung disease & $0(0)$ & $1(2.3)$ & $0(0)$ & 1.000 & 0.979 \\
\hline Newly diagnosed diabetes & $4(21.1)$ & $6(13.6)$ & $15(38.5)$ & 0.028 & 0.146 \\
\hline \multicolumn{6}{|l|}{ Origin } \\
\hline Cryptogenic & $15(78.9)$ & $38(86.4)$ & $39(100.0)$ & 0.008 & 0.008 \\
\hline Biliary tract origin & $1(5.3)$ & $5(11.4)$ & $0(0)$ & 0.068 & 0.287 \\
\hline \multicolumn{6}{|l|}{ Abscess locations } \\
\hline Right lobe & $11(57.9)$ & $23(52.3)$ & $21(53.8)$ & 0.442 & 0.214 \\
\hline Left lobe & $5(26.3)$ & $13(29.5)$ & $6(15.4)$ & & \\
\hline Both lobes & $3(15.8)$ & $8(18.2)$ & $12(30.8)$ & & \\
\hline \multicolumn{6}{|l|}{ Abscess size } \\
\hline$<5 \mathrm{~cm}$ & $9(47.4)$ & $18(40.9)$ & $18(46.2)$ & 0.962 & 0.829 \\
\hline $5 \sim 10 \mathrm{~cm}$ & $9(47.4)$ & $21(47.7)$ & $18(46.2)$ & & \\
\hline$>10 \mathrm{~cm}$ & $1(5.3)$ & $5(11.4)$ & $3(7.7)$ & & \\
\hline Gas forming & $0(0)$ & $6(13.6)$ & $6(15.4)$ & 0.218 & 0.317 \\
\hline Multiple abscesses & $8(42.1)$ & $12(27.3)$ & $17(43.6)$ & 0.256 & 0.308 \\
\hline \multicolumn{6}{|l|}{ Initial laboratory value } \\
\hline Leukocyte count, $\times 10^{3} / \mu \mathrm{L}$ & $12.4 \pm 3.8$ & $14.4 \pm 5.6$ & $12.4 \pm 6.2$ & 0.168 & 0.225 \\
\hline Platelet, $\times 10^{3} / \mu \mathrm{L}$ & $195 \pm 87$ & $222 \pm 102$ & $237 \pm 140$ & 0.380 & 0.734 \\
\hline C-reactive protein, $\mathrm{mg} / \mathrm{dL}$ & $18.8 \pm 9.2$ & $19.3 \pm 9.6$ & $20.9 \pm 10.1$ & 0.539 & 0.826 \\
\hline Glucose, mg/dL & $193 \pm 76$ & $270 \pm 152$ & $371 \pm 170$ & $<0.001$ & $<0.001$ \\
\hline \multicolumn{6}{|l|}{ Treatment } \\
\hline Antibiotics + drainage & $16(84.2)$ & $37(84.1)$ & $32(82.1)$ & 1.000 & 0.779 \\
\hline Antibiotics + operation & $1(5.3)$ & $2(4.5)$ & $1(2.6)$ & 1.000 & 0.345 \\
\hline Antibiotics only & $2(10.5)$ & $6(13.6)$ & $5(13.2)$ & 1.000 & 0.524 \\
\hline Metastatic infections, & $0(0)$ & $3(6.8)$ & $9(23.1)$ & 0.021 & 0.004 \\
\hline \multicolumn{6}{|l|}{ Outcome } \\
\hline Hospitalization days & $26.3 \pm 15.7$ & $31.9 \pm 23.2$ & $24.9 \pm 12.5$ & 0.201 & 0.265 \\
\hline ICU admission & $2(10.5)$ & $5(11.4)$ & $7(17.9)$ & 0.695 & 0.605 \\
\hline Mortality & $0(0)$ & $1(2.3)$ & $2(5.1)$ & 0.785 & 0.181 \\
\hline
\end{tabular}

Data are presented as mean \pm SD or frequency with percentage (\%). 


\section{Comparison of clinical characteristics in KPLA diabetic patients according to different $\mathrm{HbA}_{1 \mathrm{c}}$ levels}

To analyze further the impact of glycemic control on the clinical characteristics of KPLA, we divided the patients into three groups according to $\mathrm{HbA}_{1 \mathrm{c}}$ level: $<7 \%, 7-10 \%$ and $>10 \%$, as shown in Table 2. A $\mathrm{HbA}_{1 \mathrm{c}}$ level $>10 \%$ suggested poorly controlled diabetes [25]. The level of $\mathrm{HbA}_{1 \mathrm{c}}$ was significantly different in the three groups ( $6.5 \pm 0.3$ vs $8.4 \pm 0.9$ vs $11.8 \pm 1.6 \%, p<0.001)$. Patients with $\mathrm{HbA}_{1 \mathrm{c}}>10 \%$ were significantly younger $(p<0.001)$ than the other two groups. Newly diagnosed diabetes, cryptogenic origin abscess, and metastatic infection were more common in the group of $\mathrm{HbA}_{1 \mathrm{c}}$ level $>10 \%$. Cryptogenic origin abscess and metastatic infection were still more common in the group of $\mathrm{HbA}_{1 \mathrm{c}}$ level > 10\% after adjustment with age.

\section{Risk factors for metastatic infections from KPLA in diabetic patients}

The rate of metastatic infection was $11.8 \%$ in diabetic KPLA ( $\mathrm{n}=12)$, and the commonest infectious site was the eyes $(n=3)$ and lungs $(n=3)$, followed by the spleen $(\mathrm{n}=2)$, kidneys $(\mathrm{n}=2)$, prostate $(\mathrm{n}=1)$, and muscle over the left thigh $(n=1)$. Two patients with metastatic infection died and the mortality rate was significantly higher than that without metastatic infection (16.7 vs $1.1 \%, p=0.036$ ). Table 3 showed the risk factors metastatic infection from KPLA. Logistic regression analysis revealed that $\mathrm{HbA}_{1 \mathrm{c}}$ level (odds ratio [OR], 1.50; 95\% confidence interval $[\mathrm{CI}], 1.01-2.25 ; p=0.047)$ abscess size $<5 \mathrm{~cm}$ (OR, 4.72; 95\% CI, 1.09-20.52; $p=0.038)$ were the independent predictors of metastatic infection.

\section{Discussion}

It is believed that several aspects of immunity are altered in patients with diabetes. For example, polymorphonuclear leukocyte function is depressed; leukocyte adherence, chemotaxis and phagocytosis may be affected; and antioxidant systems involved in bactericidal activity may also be impaired. Although these in vitro findings have not yet been fully confirmed in clinical studies, there is evidence that improving glycemic control in patients improves immune function [27]. Kornum et al. found that an elevated $\mathrm{HbA}_{1 \mathrm{c}}$ predicted increased risk for allcause community-acquired pneumonia among patients with diabetes [28]. In diabetic patients with sepsis, one study has demonstrated that $\mathrm{HbA}_{1 \mathrm{c}}$ is an independent prognostic factor for hospital mortality and length of

Table 3 Risk factors for metastatic infection of KPLA in diabetic patients

\begin{tabular}{|c|c|c|c|c|c|}
\hline \multirow[b]{2}{*}{ Factor } & \multirow{2}{*}{$\begin{array}{l}\text { No metastatic } \\
\text { infection }(n=90)\end{array}$} & \multirow{2}{*}{$\begin{array}{l}\text { Metastatic } \\
\text { infection }(n=12)\end{array}$} & \multirow{2}{*}{$\begin{array}{l}\text { Univariate analysis } \\
p \text { value }\end{array}$} & \multicolumn{2}{|l|}{ Multivariate analysis } \\
\hline & & & & Odds Ratio $(95 \% \mathrm{Cl})$ & $p$ value \\
\hline Male & $63(70.0)$ & $8(66.7)$ & 0.814 & $0.76(0.16-3.59)$ & 0.733 \\
\hline Age in years & $64.4 \pm 14.2$ & $63.2 \pm 16.0$ & 0.779 & $1.02(0.97-1.08)$ & 0.430 \\
\hline \multicolumn{6}{|l|}{ Underlying diseases } \\
\hline Malignancy & $10(11.8)$ & $1(8.3)$ & 0.772 & - & - \\
\hline Alcoholism & $4(4.8)$ & $1(8.3)$ & 0.564 & - & - \\
\hline Chronic kidney disease & $9(10.6)$ & $0(0)$ & 0.999 & - & - \\
\hline Liver cirrhosis & $2(2.2)$ & $0(0)$ & 0.999 & - & - \\
\hline Congestive heart failure & $2(2.2)$ & $0(0)$ & 0.999 & - & - \\
\hline Chronic lung disease & $1(1.1)$ & $0(0)$ & 1.000 & - & - \\
\hline Newly diagnosed diabetes & $21(23.3)$ & $4(33.3)$ & 0.453 & - & - \\
\hline $\mathrm{HbA}_{1 c}$ & $9.1 \pm 2.3$ & $11.0 \pm 2.3$ & 0.015 & $1.50(1.01-2.25)$ & 0.047 \\
\hline Cryptogenic origin & $80(88.9)$ & $12(100)$ & 0.999 & - & - \\
\hline Abscess locations in both lobes & $18(20.0)$ & $5(41.7)$ & 0.102 & $1.48(0.29-7.60)$ & 0.646 \\
\hline Abscess size $<5 \mathrm{~cm}$ & $36(40)$ & $9(75)$ & 0.032 & $4.72(1.09-20.52)$ & 0.038 \\
\hline Gas forming & $11(12.2)$ & $1(8.3)$ & 0.693 & - & - \\
\hline Multiple abscesses & $29(32.2)$ & $8(66.7)$ & 0.028 & $3.03(0.62-14.74)$ & 0.170 \\
\hline \multicolumn{6}{|l|}{ Initial laboratory value } \\
\hline Leucocyte count, $\times 10^{3} / \mu \mathrm{L}$ & $13.2 \pm 5.5$ & $13.9 \pm 6.8$ & 0.653 & - & - \\
\hline Platelet, $\times 10^{3} / \mu \mathrm{L}$ & $225 \pm 117$ & $209 \pm 113$ & 0.654 & - & - \\
\hline C-reactive protein, mg/dL & $19.5 \pm 9.6$ & $22.3 \pm 9.6$ & 0.339 & - & - \\
\hline Glucose, mg/dL & $284 \pm 150$ & $380 \pm 229$ & 0.071 & $1.00(0.99-1.00)$ & 0.728 \\
\hline
\end{tabular}

Data are presented as mean \pm SD or frequency with percentage (\%). 
stay [29]. Regarding the issue of glycemic control and KPLA, only one case series from Taiwan analyzing 6 cases of recurrent KPLA has been reported in the literature. Five of the six patients had diabetes with poor glycemic control, and four had $\mathrm{HbA}_{1 \mathrm{c}}>9 \%$ (range: $9.2-17.5 \%)$ [30]. The current study is, to the best of our knowledge, the first to investigate the effect of glycemic control on characteristics of KPLA in diabetic patients.

In our study, we found that patients with uncontrolled glycemia tended to be younger, and had the trend to have a higher rate of cryptogenic liver abscess, gas-forming liver abscess, and metastatic infection than those with controlled glycemia, although these differences did not reach significance. Young age, newly diagnosed diabetes, cryptogenic liver abscess and metastatic infection were more common in the poor glycemic control group $\left(\mathrm{HbA}_{1 \mathrm{c}}\right.$ value $>10 \%)$. Cryptogenic invasive KPLA is frequently associated with diabetes [23]; therefore, we further established that it was highly linked to diabetic patients with high level of $\mathrm{HbA}_{1 \mathrm{c}}$. The finding that younger patients with KPLA are prone to have uncontrolled glycemia has never been reported, in part due to the small sample sizes of studies reported in the literature $[6,13]$.

Lin et al. have analyzed the effect of glycemic control of type 2 diabetes on neutrophil phagocytosis of serotype $\mathrm{K} 1 / \mathrm{K} 2 \mathrm{~K}$. pneumoniae isolates. This in vitro study suggests that strict metabolic control may improve the neutrophil phagocytosis of $\mathrm{K} 1 / \mathrm{K} 2 \mathrm{~K}$. pneumoniae in patients with type 2 diabetes [31]. In the current study focusing on diabetic patients, we not only found that the rate of metastatic infection was more common in patients with poor glycemic control, but also that $\mathrm{HbA}_{1 \mathrm{c}}$ level was an independent risk factor for metastatic infection. It is also notable that there was no mortality, metastatic infection or gas-forming abscess in the group with controlled glycemia. The previous in vitro study by Lin et al. may support our clinical findings, and we suggest that $\mathrm{HbA}_{1 \mathrm{c}}$ level is detrimental in KPLA, and controlled glycemia may prevent the development of serious metastatic complications.

Previous case reports have demonstrated that diagnosis of diabetes may come to light because of KPLA $[32,33]$. It is notable that around $25 \%$ of cases were newly recognized diabetes in the current study despite improvement in diagnosis and awareness in recent years, and the existence of a comprehensive national health insurance program in Taiwan that optimizes access to medical care. Due to unrecognized diabetes complicated with infection, extreme hyperglycemia, even hyperglycemic hyperosmolar state or diabetic ketoacidosis, may occur. Physicians should not ignore the underlying diabetes in patients with KPLA in clinical practice. One particularly interesting finding in our study was that liver abscess $<5 \mathrm{~cm}$ in diabetic patients was independently associated with metastatic infection, which has not been reported in the literature. It suggested that we should not overlook the risk of complication from small sized liver abscess in diabetic patients.

We acknowledge some limitations in our study that deserve mention. First, the data were collected retrospectively from medical records. Second, participants were recruited from a medical center in Northern Taiwan, and therefore we could not evaluate possible regional variations. Further analyses should be conducted in other regions and countries to confirm our findings. Thirdly, our results were also limited by the incomplete collection of $\mathrm{HbA}_{1 \mathrm{c}}$ data. Finally, the isolates were not collected for further analysis, such as virulence factors or clonal types, in the current study. Despite these limitations, our study is believed to be the first to discuss the characteristics of KPLA due to the different level of glycemic control, which sheds further light on the association between diabetes and KPLA, and our results may partly elucidate the role of host factors in the pathogenesis of KPLA.

\section{Conclusion}

Patients with uncontrolled glycemia were significantly younger than those with controlled glycemia. Patients with uncontrolled glycemia had the trend to have a higher rate of gas-forming liver abscess, cryptogenic liver abscess and metastatic infection than those with controlled glycemia. Cryptogenic liver abscess and metastatic infection were more common in the poor glycemic control group $\left(\mathrm{HbA}_{1 \mathrm{c}}\right.$ value $\left.>10 \%\right)$. $\mathrm{HbA}_{1 \mathrm{c}}$ level and abscess $<5 \mathrm{~cm}$ were independent risk factors for metastatic complications from KPLA. Therefore, glycemic control in diabetic patients plays an essential role in the clinical features of KPLA, especially in metastatic complications from KPLA.

\section{Abbreviations}

KPLA: Klebsiella pneumoniae liver abscess; 95\% Cl: 95\% confidence interval; OR: Odds ratio; $\mathrm{HbA}_{1 \mathrm{c}}$ : Hemoglobin A1c.

\section{Competing interests}

All authors declare that they have no conflict of interest.

\section{Authors' contributions}

YTL conceived of the study, and participated in its design and coordination. YTL, FDW, PFW and CPF performed the laboratory experiments, reviewed and collected the data. YTL analyzed and interpreted the data. YTL and PFW drafted the manuscript. FDW and CPF reviewed the manuscript. All authors read and approved the final manuscript.

\section{Acknowledgements}

This study was partly supported partly by grants from Taipei Veterans General Hospital (V101A-029 and V101C-017).

The authors thank Ms. Chiu-Mei Yeh for her endorsement and assistance in our statistical analyses.

Received: 28 July 2012 Accepted: 28 January 2013

Published: 30 January 2013 


\section{References}

1. Kim JK, Chung DR, Wie SH, Yoo JH, Park SW: Risk factor analysis of invasive liver abscess caused by the K1 serotype Klebsiella pneumoniae. Eur J Clin Microbiol Infect Dis 2009, 28:109-111.

2. Chung DR, Lee SS, Lee HR, Kim HB, Choi HJ, Eom JS, Kim JS, Choi YH, Lee JS, Chung MH, Kim YS, Lee H, Lee MS, Park CK, Korean Study Group for Liver Abscess: Emerging invasive liver abscess caused by K1 serotype Klebsiella pneumoniae in Korea. J Infect 2007, 54:578-583.

3. Yeh KM, Kurup A, Siu LK, Koh YL, Fung CP, Lin JC, Chen TL, Chang FY, Koh $\mathrm{TH}$ : Capsular serotype $\mathrm{K} 1$ or $\mathrm{K} 2$, rather than magA and $r \mathrm{mpA}$, is a major virulence determinant for Klebsiella pneumoniae liver abscess in Singapore and Taiwan. J Clin Microbiol 2007, 45:466-471.

4. Lok KH, Li KF, Li KK, Szeto ML: Pyogenic liver abscess: clinical profile, microbiological characteristics, and management in a Hong Kong hospital. J Microbiol Immunol Infect 2008, 41:483-490.

5. Fung CP, Chang FY, Lee SC, Hu BS, Kuo BI, Liu CY, Ho M, Siu LK: A global emerging disease of Klebsiella pneumoniae liver abscess: is serotype K1 an important factor for complicated endophthalmitis? Gut 2002, 50:420-424.

6. Fang CT, Lai SY, Yi WC, Hsueh PR, Liu KL, Chang SC: Klebsiella pneumoniae genotype K1: an emerging pathogen that causes septic ocular or central nervous system complications from pyogenic liver abscess. Clin Infect Dis 2007, 45:284-293.

7. Kohayagawa Y, Nakao K, Ushita M, Niino N, Koshizaki M, Yamamori Y, Tokuyasu Y, Fukushima H: Pyogenic liver abscess caused by Klebsiella pneumoniae genetic serotype K1 in Japan. J Infect Chemother 2009, 15:248-251.

8. Tsai FC, Huang YT, Chang LY, Wang JT: Pyogenic liver abscess as endemic disease, Taiwan. Emerg Infect Dis 2008, 14:1592-1600.

9. Lin YT, Liu CJ, Chen TJ, Chen TL, Yeh YC, Wu HS, Tseng CP, Wang FD, Tzeng $\mathrm{CH}$, Fung CP: Pyogenic liver abscess as the initial manifestation of underlying hepatocellular carcinoma. Am J Med 2011, 124:1158-1164.

10. Lin YT, Liu CJ, Chen TJ, Fung CP: Long-term mortality of patients with septic ocular or central nervous system complications from pyogenic liver abscess: A population-based study. PLoS One 2012, 7(3):e33978.

11. Liu YC, Cheng DL, Lin CL: Klebsiella pneumoniae liver abscess associated with septic endophthalmitis. Arch Intern Med 1986, 146:1913-1916.

12. Cheng DL, Liu YC, Yen MY, Liu CY, Wang RS: Septic metastatic lesions of pyogenic liver abscess. Their association with Klebsiella pneumoniae bacteremia in diabetic patients. Arch Intern Med 1991, 151:1557-1559.

13. Lee SS, Chen YS, Tsai HC, Wann SR, Lin HH, Huang CK, Liu YC: Predictors of septic metastatic infection and mortality among patients with Klebsiella pneumoniae liver abscess. Clin Infect Dis 2008, 47:642-650.

14. Sheu SJ, Kung YH, Wu TT, Chang FP, Horng YH: Risk factors for endogenous endophthalmitis secondary to Klebsiella pneumoniae liver abscess: 20-year experience in southern Taiwan. Retina 2011, 31:2026-2031

15. Yang PW, Lin HD, Wang LM: Pyogenic liver abscess associated with septic pulmonary embolism. J Chin Med Assoc 2008, 71:442-447.

16. Muller LM, Gorter KJ, Hak E, Goudzwaard WL, Schellevis FG, Hoepelman Al, Rutten GE: Increased risk of common infections in patients with type 1 and type 2 diabetes mellitus. Clin Infect Dis 2005, 41:281-288.

17. Thomsen RW, Jepsen P, Sørensen HT: Diabetes mellitus and pyogenic liver abscess: risk and prognosis. Clin Infect Dis 2007, 44:1194-1201.

18. Foo NP, Chen KT, Lin HJ, Guo HR: Characteristics of pyogenic liver abscess patients with and without diabetes mellitus. Am J Gastroentero/ 2010, 105:328-335.

19. Wang JH, Liu YC, Lee SS, Yen MY, Chen YS, Wang JH, Wann SR, Lin HH: Primary liver abscess due to Klebsiella pneumoniae in Taiwan. Clin Infect Dis 1998, 26:1434-1438.

20. Lin YC, Lu MC, Tang HL, Liu HC, Chen CH, Liu KS, Lin C, Chiou CS, Chiang MK, Chen CM, Lai YC: Assessment of hypermucoviscosity as a virulence factor for experimental Klebsiella pneumoniae infections: comparative virulence analysis with hypermucoviscosity-negative strain. $B M C$ Microbiology 2011, 11:50

21. Yang CS, Tsai HY, Sung CS, Lin KH, Lee FL, Hsu WM: Endogenous klebsiella endophthalmitis associated with pyogenic liver abscess. Ophthalmology 2007, 114:876-880. e2.

22. Chen SC, Lee YT, Lai KC, Cheng KS, Jeng LB, Wu WY, Wu WY, Chen CC, Lee MC: Risk factors for developing metastatic infection from pyogenic liver abscesses. Swiss Med Wkly 2006, 136:119-126.
23. Braiteh F, Golden MP: Cryptogenic invasive Klebsiella pneumoniae liver abscess syndrome. Int J Infect Dis 2007, 11:16-22.

24. Lee CJ, Jung DS, Jung SH, Baik JH, Lee JH, Cho YR, Go BS, Lee SW, Han SY, Lee DH: Comparison of liver abscess between diabetic patients and nondiabetic patients. Korean J Hepatol 2005, 11:339-349.

25. American Diabetes Association: Standards of medical care in diabetes2009. Diabetes Care 2009, 32(1):S13-S61.

26. Mark S: Glycemic control and complications in type 2 diabetes mellitus. Am J Med 2010, 123:S3-S11.

27. Joshi N, Caputo GM, Weitekamp MR, Karchmer AW: Infections in Patients with Diabetes Mellitus. N Engl J Med 1999, 341:1906-1912.

28. Kornum JB, Thomsen RW, Riis A, Lervang HH, Schønheyder HC, Sørensen $H T$ : Diabetes, glycemic control, and risk of hospitalization with pneumonia: a population-based case-control study. Diabetes Care 2008, 31:1541-1545

29. Gornik I, Gornik O, Gasparovic V: $\mathrm{HbA}_{1 \mathrm{c}}$ is outcome predictor in diabetic patients with sepsis. Diabetes Res Clin Pract 2007, 77:120-125.

30. Yang YS, Siu LK, Yeh KM, Fung CP, Huang SJ, Hung HC, Lin JC, Chang FY: Recurrent Klebsiella pneumoniae liver abscess: clinical and microbiological characteristics. J Clin Microbiol 2009, 47:3336-3339.

31. Lin JC, Siu LK, Fung CP, Tsou HH, Wang JJ, Chen CT, Lin JC, Chang FY: Impaired phagocytosis of capsular serotypes K1 or K2 Klebsiella pneumoniae in type 2 diabetes mellitus patients with poor glycemic control. J Clin Endocrinol Metab 2006, 91:3084-3087.

32. Lederman ER, Crum NF: Pyogenic liver abscess with a focus on Klebsiella pneumoniae as a primary pathogen: an emerging disease with unique clinical characteristics. Am J Gastroenterol 2005, 100:322-331.

33. Saccente M: Klebsiella pneumoniae liver abscess, endophthalmitis, and meningitis in a man with newly recognized diabetes mellitu. Clin Infect Dis 1999, 29:1570-1571.

\section{doi:10.1186/1471-2334-13-56}

Cite this article as: Lin et al:: Klebsiella pneumoniae liver abscess in diabetic patients: association of glycemic control with the clinical characteristics. BMC Infectious Diseases 2013 13:56.

\section{Submit your next manuscript to BioMed Central and take full advantage of:}

- Convenient online submission

- Thorough peer review

- No space constraints or color figure charges

- Immediate publication on acceptance

- Inclusion in PubMed, CAS, Scopus and Google Scholar

- Research which is freely available for redistribution 